\title{
Cultural meanings of ethnic categories
}

\author{
Matthew Hodes, Jayne Creamer and James Woolley
}

\begin{abstract}
This study investigated the links between aspects of cultural life and response to ethnic monitoring questions, and compared parental and adolescents' responses. Questionnaires were given to consecultive attenders at a child and adolescent poychiatiy department stuated in central London. Forty-seven parents participated, and 24 adolescents (aged 12-16 years) also completed questionnaires. Parents came from many parts of the world and their oftspring were mostly born in the UK, but had varied cultural life with respect to language, peer group and diet. Just over half of the offepring were regarded as 'White British' by parents but the second largest group was that marked 'other', who all had mixed identity. There were differences in how parents described adolescents, especially in relation to peer culture. Since ethnic categories have limitations the data should be used carefully, and for many aspects of health planning and delivery other cultural variables would be useful. Consideration should be given to the need for specilying whother adolescents or their parents should respond to ethnic monitioring questions.
\end{abstract}

Ethnicity has emerged as an important epidemiological variable (Senior \& Bhopal, 1994). It is useful in understanding the distribution of disorders in communities, their aetiology and evaluating health service delivery and access (Balarajan \& Raleigh. 1993). Nevertheless, the concept of ethnic identity and the issue of ethnic monitoring within the National Health Service are controversial. This is partly due to the introduction in April 1995 of the Department of Health's mandatory collection of ethnic group data of patients admitted to hospital, and their widespread use in out-patient settings. There is also controversy concerning the census headings that are used for monitoring in health settings (Senior \& Bhopal, 1994). These issues are particularly pertinent for mental health services in view of the controversy surrounding associations between ethnicity, psychiatric diagnosis and equitable access to diverse treatments (Fernando, 1995).

A consistent set of categories for ethnic monitoring is needed, and yet those in use have serious limitations. Important problems are that many ethnic minorities may feel forced to choose a category, or will choose 'other' and suggest a category that will not be used in data analysis (Aspinall, 1995). This could be a problem for purchasers and health providers who may be using ethnic monitoring data which do not describe particular ethnic groups which are large enough to justify special attention at a local level. for example the Vietnamese community in South London (Aspinall, 1995). Another problem concerns the fact that ethnic categories may apparently homogenise people from ethnic minorities. An example is the category 'Black AfroCaribbean', which could be used to describe people who come from one geographical area although there are at least four different languages spoken there, with at least as many cultural influences (Hutchinson \& McKenzie, 1995).

Ethnic identity occurs as a result of selfattribution and attributions by others (Banton, 1977. 1983). Ethnicity refers to the range of attributes that make distinctions between social groups (Barth, 1969). These attributes are drawn from many cultural domains such as religion, language and kinship. The cultural distinctions are associated with economic and political differences, so that ethnicity, culture and social class may overlap (Banks, 1996). Within this complex matrix, ethnicity is constantly changing as the minority communities develop and the relationship with the dominant culture and country of origin alters (Ballard, 1994). This means that people will constantly be changing how they perceive and describe themselves. In addition there may also be generational differences (Ballard, 1994; Baumann, 1995).

Given that ethnicity is constituted through a variety of meanings and contexts, any one way to describe it will have some limitations. From the point of view of health planning a range of data may be required (Senior \& Bhopal, 1994). Useful variables may include country of birth, language, diet and religion. It is also useful to collect data about socio-economic status which can be an important confounder in analysis of ethnic data. While it is now usual practice for the data to be provided by self-report, there has been little consideration about young people in the adolescent age range and whether they should provide this data, or their parents. 
In order to clarify these issues, this study aimed to explore the different aspects of ethnic identity, and relate them to responses on the existing ethnic categories. The second aim was to assess whether parents and adolescent offspring use different ways to describe the adolescents' ethnic identity.

\section{The study}

All children and at least one parent attending St Mary's Department of Child and Adolescent Psychiatry, London, for the first time were eligible. This involved far fewer families than the numbers referred to the department, because many were seen at the St Mary's Hospital site, or did not attend for their initial appointments at the Department of Child and Adolescent Psychiatry. The families were provided with an information sheet explaining the rationale and aims of the study and requesting participation. Concerns about the study were clarified at the time of attendance in the department. Parents were asked to complete questionnaires, and also adolescent children ( 12 years or older) were given questionnaires so their responses could be compared with their parents.

The study utilised a questionnaire and a proforma, at the time of attendance. The questionnaire regarding children's culture was derived from the one developed by Pumariega in the USA (Pumariega, 1986). This questionnaire was originally developed as a measure of acculturation to quantify the extent to which Hispanic female adolescents living in the USA had adopted White American culture. Two similar versions of the culture questionnaire were used, one for the adolescent and one for the parent(s). The first question asked parents 'How would you describe him/her in terms of social/ethnic group or social/economic position?'. The first question for adolescents was 'How would you describe yourself in terms of social/ethnic group or social/economic position?'. The other questions are apparent from Table 2, which links the questions to the responses. The tenth and final question is the same as that used for ethnic monitoring in the National Health Service. (A copy of the questionnaire is available from $M . H$. upon request.) Basic socio-demographic data regarding the parents were collected on a proforma.

The data were analysed using SPSS for windows (Norusis, 1993). Data analysis involved descriptive statistics.

\section{Findings}

Over the 12-month period of this study 98 parents were eligible for inclusion. The largest group not included was 36 parents and offspring who did not attend for the initial appointments offered, and contact with them could not be made by the investigators. Six cases were not included because the investigators could not be present in the department at the time of their attendance. Five parents were not approached on the recommendation of the clinicians involved with their care. One parent refused to participate, and one could not speak English and an interpreter was not present. For two adolescents parents did not participate. The remaining 47 parents and children participated, but in two cases parents were not involved, but questionnaires were completed by adolescents attending alone.

The parents had diverse backgrounds: 15 fathers had manual occupations, 13 non-manual, and three made no response to this question. The parents had been born in varied parts of the world, as can be seen in Table 1 .

For 37 parents who responded. country of birth was the same for 22 couples (59.5\%). Using ethnic categories, 16 couples out of 35 (45.7\%) scored the same. The mean age of the mothers was 39.3 years (s.d. 7.8), and for fathers the mean age was 43.1 years (s.d. 7.5).

Among the 49 children for whom help was sought, 25 were male and 24 female. The mean age of the children was 10.2 years (s.d. 4.4), with a range of 1.0-16.0 years. Twenty-six of the children were in the adolescent age range, defined here as 12-16 years. The 49 children and adolescents attended for diverse problems. the disorders falling into the following ICD-10 categories: F20-29 schizophrenia, schizotypal and delusional disorders, 1; F30-39 mood (affective) disorders, 4; F40-48 neurotic, stress related and somatic disorders, 15; F50-59 eating and sleep disorders, 7; F70-79 mental retardation, 3; F80-89 disorders of psychological development (e.g. autism), 2: F90-92 hyperkinetic and conduct disorders, 9; F93-94 emotional disorders, and disorders of social functioning, 2; F95-98 tic disorders, and non-organic enuresis and encopresis, 2; no disorder, 4.

Table 1. Country of bith of parents

\begin{tabular}{|c|c|c|}
\hline & $\begin{array}{l}\text { Mothers } \\
n(\%)\end{array}$ & $\begin{array}{l}\text { Fathers } \\
n(\%)\end{array}$ \\
\hline $\begin{array}{l}\text { UK } \\
\text { Europe or North America } \\
\text { Middle East/North Africa } \\
\text { Sub-Saharan Africa } \\
\text { Asia } \\
\text { South America } \\
\text { Carlbbean } \\
\text { No response }\end{array}$ & $\begin{aligned} 13 & (31.0) \\
12 & (28.6) \\
6 & (14.3) \\
2 & (4.8) \\
4 & (9.5) \\
1 & (2.4) \\
0 & (0) \\
4 & (9.5)\end{aligned}$ & $\begin{array}{rr}16 & (37.2) \\
13 & (30.2) \\
2 & (4.7) \\
3 & (7.0) \\
3 & (7.0) \\
2 & (4.7) \\
2 & (4.7) \\
2 & (4.7)\end{array}$ \\
\hline Total & $42(100)$ & $43(100)$ \\
\hline
\end{tabular}


Parental responses to the culture questionnaire are shown in Box 1 . These responses were divided into the following categories: appearance, where there was description of skin colour; region, where a country or geographical area was given; economic, where class or money were indicated; and personality, when personality attributes were given. Many responses referred to attributes from more than one category. The combinations are: region with appearance (e.g. English White); region with appearance and economic status (e.g. White, English middle class); economic with region (e.g. middle class English-Ghanaian-Lebanese, or working class Irish); economic with appearance (e.g. White middle class).

The responses to the other questions in the cultural questionnaire are shown, except for question seven concerning clothes and cos- metics. This question resulted in such varied responses that they could not be ordered into coherent categories, or any pattern identified, so the responses have been omitted. The response to question 10 showed that there were 33 responses from the suggested categories (White British 28; White Irish 2; Black Afro-Caribbean 1; Indian/ Pakistani/Bangladeshi, 2). Fourteen were responses from categories provided by the parent.

The response of the parents and adolescents can be compared for the 24 adolescents who completed questionnaires. The extent to which there are differences in response between adolescents and their parents is shown in Table 2.

The details of the differences to question 1 are shown in Table 3.

Comparison of parents' with adolescents' responses may vary according to the question they

\section{Box 1. Parents' responses to culture questionnaire $(n=47)$}

Question 1. Description of child ...

\begin{tabular}{lcc}
\hline & Single attribute & Combined attribute \\
\hline Appearance & 4 & 9 \\
Reglon & 19 & 10 \\
Economic & 2 & 9 \\
Personality & 4 & 0 \\
\hline
\end{tabular}

Question 2. Child born in UK? ... yes $(n=41)$, no $(n=6)$. Region if not UK: Eire/Europe ( $n=2)$, Middle East $(n=1)$, Sub-Saharan Africa $(n=1)$ (no response $(n=1)$ ). If not born in UK, mean time of residence in $\mathrm{UK}=4.7$ years.

Question 3. Language spoken at home? ... English ( $n=33)$, not English $(n=14)$. If not English, how often are other languages spoken? ... All of the time $(n=1)$, most of the time $(n=3)$, equally with English $(n=4)$, sometimes $(n=5)$ (no response $(n=1)$ ).

Question 4. Language spoken mostly with friends?... English ( $n=46)$, no English ( $n=0)$ (no response $(n=1))$.

Question 5. Does he/she think in English?...yes $(n=44)$, no ( $n=1$; Russian) (no response $(n=2))$.

Question 6. Type of food he/she eats? ... food item-specific (e.g. beans, chicken) ( $n=5)$, culturespecific (e.g. Indian, English) ( $n=24)$, generic (e.g. anything, international) $(n=18)$.

Question 8. Are his/her friends mostly English?...yes $(n=36)$, no $(n=11)$. If yes, how many? .. some $(n=13)$, most $(n=2)$, all $(n=2)$, (no response $(n=19)$ ).

Question 9. Are these English people married into the family? ... yes $(n=36)$, no $(n=11)$. If yes, how many?... some $(n=13)$, most $(n=2)$, all $(n=2)$ (no response $(n=19))$.

Question 10. Do you consider him to be ... White British ( $n=28)$. White Irish ( $n=2)$. Black African $(n=0)$, Black Afro-Caribbean $(n=1)$, Indian/Pakistani/Bangladeshi $(n=2)$, Asian other $(n=0)$, other ( $n=14$; Anglo-Iranian ( $n=2)$, Black British, White European, White Brazilian, AfroArab, Eurasian, Fllipino-British, Euro-Caribbean, Sri Lankan, Irish/Scottish, Anglo-Arab, British Ghanian, mixed ( $n=1$ each)). 
Table 2. Responses from adolescents and their parents about the adolescents $(n=24)$

\begin{tabular}{|c|c|c|c|}
\hline & & $\begin{array}{l}\text { Adolescent } \\
\text { response }\end{array}$ & $\begin{array}{l}\text { Different } \\
\text { parent } \\
\text { response }\end{array}$ \\
\hline Question 1. & Self description & 24 & 9 \\
\hline Question 2. & Born in the UK & 21 & 1 \\
\hline $\begin{array}{c}\text { Question 3. } \\
\text { at home }\end{array}$ & Only speak English & 22 & 3 \\
\hline $\begin{array}{l}\text { Question 4. ' } \\
\text { with friends }\end{array}$ & $\begin{array}{l}\text { Mostly speak English } \\
\text { s }\end{array}$ & 24 & 0 \\
\hline Question 5. & Think in English & 24 & 1 \\
\hline Question 6. & Type of food eaten & 24 & 8 \\
\hline $\begin{array}{l}\text { Question } 8 . \\
\text { English }\end{array}$ & Friends mostly & 18 & 6 \\
\hline $\begin{array}{l}\text { Question } 9 . \\
\text { married intc }\end{array}$ & $\begin{array}{l}\text { English people } \\
\text { to family }\end{array}$ & 16 & 9 \\
\hline $\begin{array}{l}\text { Question } 10 . \\
\text { Question } 10 .\end{array}$ & $\begin{array}{l}\text { White British } \\
\text { Other responses }\end{array}$ & $\begin{array}{r}15 \\
9\end{array}$ & $\begin{array}{l}0 \\
3\end{array}$ \\
\hline
\end{tabular}

Table 3. Self-description by adolescents and parental description compared $(n=24)^{\prime}$

\begin{tabular}{|c|c|c|c|c|}
\hline & \multicolumn{2}{|c|}{ Adolescents } & \multicolumn{2}{|l|}{ Parents } \\
\hline & $\begin{array}{l}\text { Single } \\
\text { atinibute }\end{array}$ & $\begin{array}{l}\text { Combined } \\
\text { attribute }\end{array}$ & $\begin{array}{l}\text { Single } \\
\text { altibute }\end{array}$ & $\begin{array}{l}\text { Combined } \\
\text { attribute }\end{array}$ \\
\hline Appearance & 2 & 5 & 1 & 6 \\
\hline Region & 7 & 2 & 8 & 3 \\
\hline Economic & 0 & 3 & 2 & 5 \\
\hline Personality & 5 & 0 & 3 & 0 \\
\hline
\end{tabular}

1. Seven adolescents and three parents did not respond.

are answering. To address this issue, comparison can be made between their responses to open question of the culture questionnaire and the closed question used for ethnic monitoring. For question one, there was agreement between the parents in 15 cases, and disagreement in nine $(n=24)$, whereas, for the closed question 10 . there was a higher level of agreement, in 21 out of 24 cases $(P<0.1)$.

\section{Comment}

This study of attenders at a child and adolescent psychiatry department situated in central London involved parents who came from all over the world and there was a high level, approximately half, being culturally mixed unions. They describe their offspring in very diverse ways, referring to appearance, region. economic position and personality. Although most of the children were born in the UK $(87.2 \%)$, a significant minority did not come from predominantly English-speaking house- holds (29.8\%). Almost all these children spoke English with their friends $(97.9 \%)$, although some had mostly non-English friends (23.4\%). As far as selection of ethnic categories was concerned, just over half $(59.6 \%)$ of these children were reported to be 'White British' by their parents. The second largest category, $(29.8 \%)$ scored 'other', and recorded mixed identities. There were significant differences when adolescents responded to these questions, especially regarding self-description, type of food eaten and whether the peer group was mostly English. The parent adolescent agreement regarding these questions tended to be greater for the closed questions, for example the questions used for ethnic monitoring.

The data from this study suggest that in the inner cities, where there are many immigrants, many health service users will not be using the main ethnic categories to describe themselves or their offspring. The high proportion of children and adolescents regarded as having mixed identity is in keeping with recent research that suggests that adolescents take some aspects of their cultural identity from their parents but are also active participants in constructing new identities (Tizard \& Phoenix, 1993; Ballard, 1994: Baumann, 1995).

At a practical level, the results indicate that health planning and the development of services cannot ignore this large group. Currently data suggest this group may be omitted from health planning. This creates difficulties interpreting ethnic data, consistent with larger studies (Aspinall, 1995). Furthermore, many important aspects of cultural life are not identified by existing categories. They give no indication of languages spoken. There are differences between parents' and adolescents' responses to the questions asked in assessment of cultural life, especially when open questions are asked or there is inquiry about adolescents' involvement with peers. Even with the closed question used for ethnic monitoring, there are differences in how adolescents and parents score ethnicity for the non-White British group.

The main limitation of this study is the small study population. It is unclear whether parents and adolescents presenting in other health services would respond differently to these questionnaires. Further study of these issues would be important.

The findings of this study suggest that responses to ethnic monitoring should be interpreted cautiously. Collection of ethnic monitoring data should be accompanied by consideration of how the data will be used. Other variables such as country of birth, and first language would be important for many studies. To reduce variability in the way ethnic monitoring is carried out there should be guidelines as to 
whether adolescents or their parents respond to the questions.

\section{Acknowledgements}

We are grateful to all members of the St Mary's Department of Child and Adolescent Psychiatry who assisted and supported this study, and also to all the adolescents and parents who took part.

\section{References}

ASPINALL, P. J. (1995) Department of Health's requirement for mandatory collection of data on ethnic group of inpatients. British Medical Journal, 311, 1006-1009.

BALARAJAN, R. \& RALEIGH, V. S. (1993) Ethnicity and Health London: Department of Health.

BALLARD. R. (1994) Desh Pradesh. The South Asian Presence in Britain. London: Hurst.

BANKS, M. (1996) Ethnicity: Anthropological Constructions. London: Routledge.

BANTON, M. (1977) The Idea of Race. London: Tavistock.

- (1983) Racial and Ethnic Competition. Cambridge: Cambridge University Press.

BARTH, F. (1969) Ethnic Groups and Boundarles: the Social Organisation of Culture Difference. Bergen and London: Universitets Forlaget and George Allen and Unwin.
BAUMANN, G. (1995) Managing a polyethnic milieu: kinship and interaction in a London suburb. Journal of the Royal Anthropological Institute (N.S.), 1. 725-741.

FERNANDO, S. (1995) Mental Health in a Multi-Ethnic Society. London: Routledge.

HutCHINSON, G. \& MCKENZE, K. (1995) What is an AfroCaribbean? Implications for psychiatric research. Psychiatric Bulletin, 19, 700-702.

NORUSIS, M. J. (1993) SPSS for Windows. Chicago: SPSS.

PumAriegA, A. J. (1986) Acculturation and eating attitudes in adolescent girls: a comparative and correlational study. Journal of the American Academy of Child and Adolescent Psychiatry. 25, 276-279.

SENIOR, P. \& BHOPAL, R. (1994) Ethnicity as a variable in epidemiological research. British Medical Journal, $\mathbf{5 0 9}$ 327-330.

TIZARD, B. \& PHOENIX, A. (1993) Black, White or Mixed Race? London: Routledge

*Matthew Hodes, Senior Lecturer in Child and Adolescent Psychiatry, Academic Unit of Child and Adolescent Psychiatry. Imperial College School of Medicine at St Mary's, Norfolk Place, London W2 1PG; Jayne Creamer, Research Assistant, Academic Unit of Child and Adolescent Psychiatry, Imperial College School of Medicine at St Mary's, London; James Woolley, House Physician, Ealing Hospital, London

*Correspondence 